\title{
ESTRUCTURACIÓN POLÍTICA DE CHILE EN EL SIGLO XIX
}

\author{
Hernán Villablanca Zurita ${ }^{1}$
}

Para iniciar nuestro examen de la estructura política del país entre 1830 y 1890 nos plantearemos el siguiente interrogante: ¿quién o quienes, qué clase, clases o fracciones de clase eran las que tuvieron el poder político y controlaron el aparato estatal durante el período en estudio?. Se puede decir que con la derrota de las fuerzas liberales en Lircay, a comienzos del año 1830, el poder político, el gobierno, pasó a manos de la oligarquía terrateniente y de una fracción de la burguesía mercantil chilena representada por los "estanqueros". A partir de entonces se inicia un proceso de organización y estructuración del Estado que algunos historiadores llaman "Portaliano", pero que. a nuestro juicio, su denominación debe ajustarse más exactamente al carácter de las clases o fracciones de clase que tienen el poder.

Hasta los años sesenta-ochenta un elemento constante en el ejercicio del control y poder político lo constituye la oligarquía terrateniente, variando, en cambio, la composición clasista de los otros políticos que comparten con ella dicho dominio.

Las primeras medidas políticas efectuadas inmediatamente después de la batalla de Lircay reafirmaron la alianza entre las fuerzas socio-políticas triunfantes. Los grupos terratenientes del centro y sur del país quedaron representados a través del general Joaquín Prieto, designado presidente de la República en el año 1831, con lo cual controlaba prácticamente todo el aparato político del país. La fracción de la burguesía mercantil, los estanqueros, obtuvieron el control de la economía al hacerse cargo del Ministerio de Hacienda (M. Rengifo). Al mismo tiempo, y cumpliendo el compromiso contraído con la Iglesia, una de las primeras medidas del Gobierno fue la derogación de las leyes sobre secuestro y venta de los bienes regulares, y en devolución a sus antiguos poseedores.

En el año 1833 se aprobó la nueva Constitución, expresándose en ella los rasgos básicos del Estado que se desea organizar. Parece haber un gran coincidencia entre diversos historiadores y juristas en cuanto a considerar esta Constitución como la expresión de un gobierno fuerte y autoritario, de inspiración conservadora y no democrática ${ }^{2}$. El poder polí-

' Dr. Sci., Académico del Departamento de Sociologia de la Universidad de Chile

2 Julio Heise G. "150 años de Evolución Institucional". op. cit.. p. 43: Nahun Theoduloz V. "Estudio del Senado Chileno", op. cit. pp. 107 - 109. Por otro lado, sin embargo, historiadores como D. Barros A. y Alberto Edwards V., aunque reconocen el carácter autoritario -con un gobierno fuerte y central-, e incluso conservador de la Constitución de 1833 , estiman que ello era lo que mejo: correspondía a la situación socio-política y culural del país (I). Barros A. op. cit., vol 16, pp. 332 - 36; y A. Edward V.. "La Organización Política de Chile", Santiago, 1955. pp. 114 - 37 . 
tico se concentró en el poder ejecutivo, en el primer mandatario ("un ciudadano con el título de Presidente de la República de Chile administra el Estado, y es el Jefe Supremo de la Nación"), quien puede ser reelegido, puede remover a su voluntad a los ministros dispone de veto absoluto en la formación de las leyes, y sólo el Presidente de la República puede convocar a sesiones extraordinarias y prorrogar éstas 3 . De acuerdo a esta Constitución el Poder Legislativo reside en el Congreso Nacional, compuesto de dos Cámaras, una de Diputados y otra de Senadores. Podían ser diputados los ciudadanos con derecho a sufragio (mayores de veinticinco años si son solteros, o de veintiuno si son casados), y para ser Senador se requería ciudadanía en ejercicio, treinta y seis años cumplidos, no haber sido condenado jamás por delito, y una renta de dos mil pesos "a lo menos".

Este último requisito excluía en la práctica a todos los sectores sociales de bajos ingresos, favoreciendo únicamente a los grupos oligárquicos del país. A su vez el sistema de elección indirecta establecido por la Constitución reforzaba aún más el predominio de estos grupos: "El Congreso Pleno calificaba a los electores de Presidente con lo cual la elección prácticamente quedaba radicado en el Congreso Pleno. En efecto, si el resultado de la elección contrariaba las preferencias del Congreso, la mayoría con o sin motivo, con toda impudicia, anulaba electores hasta dejar a los dos candidatos sin mayoría requerida, caso en el cual correspondía realizar la elección al Congreso Pleno. En esta forma el régimen de calificar los poderes por medio del Congreso, hizo que se llevara a la elección de Presidente el interés de cometer fraudes, ya que éstos quedaban sin sancionar, porque la elección fraudulenta no se repetía"s. Este círculo de mantención y de continua reproducción del poder político de la oligarquía se cerraba en si mismo con la facultad que otorgaba la ley electoral de diciembre de 1833 al Poder Ejecutivo de poder intervenir en todas y cada una de las etapas del proceso electoral: "En consecuencia, el Parlamento resultaba hechura del primer mandatario". De este modo el poder ejecutivo y el legislativo quedaron circunscritos al predominio de unas cuantas familias, unidas a su vez por lazos de parentesco. Se ha constatado que entre 1831 y 1927 una sola familia (Errázuriz) contribuyó con cuatro presidentes y 59 parlamentarios. Al mismo tiempo, se ha podido comprobar, que en el mismo período, de un total de 599 diputados y senadores se dieron 98 casos de hermanos, 61 de padre e hijos, 57 de tíos y sobrinos, 20 de primos, 12 suegros y yernos, y 32 de cuñados?

El carácter restringido y oligárquico de la constitución de 1833 se expresa también a través de su artículo $N^{\circ} 8$ mediante el cual se consagró el sufragio censitario, limitando el ejercicio de la soberanía a los propietarios de un bien raíz o de un determinado capital en giro, y a los que ejercían un arte o una renta o empleo equivalente por sus emolumentos al valor de esa propiedad. Esta disposición, complementada por la ley electoral de ese mismo año, comenzaba por prescribir las reglas para ser calificado como ciudadano activo y que regulaba el funcionamiento de las Juntas Calificadoras, entregaba el ejercicio del sufragio a

\footnotetext{
${ }^{3} J$. Heise, pp. cit, p. 44.

${ }^{4}$ Ramón Sotomayor V., "Historia de Chile". op. cit., pp. 242 y 244. y N. Theoduloz. op. cit., p.28

"Julio Heise G., "La Constitución de 1925 y las Nuevas Tendencias Político-Sociales". en "Anales de la Universidad de Chile" 1950, No 80 . pp. 144-45.

'J. Heise, "150 años de Evolución... op. cit. p. 45. A su vez, Ricardo Donoso sostiene que "El Senado Constituye un cuert esencialmente oligárquico, cerrado... Constituyó así un cuerpo de exclusiva designación del ejecutivo, organización que tuvo has: la reforma de 1874 , con lo que el poder legislativo quedó completamente anulado. La legislatura quedó así subordinada al Presider:de la República, ya que ninguna ley que se opusiese a sus propósitos encontraría la sanción de la cámara alta. Desde entonces : hubo solo senador que no fuera nombrado por el gobierno, que nadaba sus listas a las provincias seguro de ser obedecido". Donoso, op. cit., 108). De acuerdo a D. Barros Arana, la elección de senadores, indirecta con arreglo a la Constitución de $183 \hat{3}$ podía dar el triunfo a la oposición, a no ser que ésta tuviese en sus manos a la mayoría de los colegios electorales de modo que h.: la reforma constitucional de 1874 "jamás pudo llegar al senado un solo candidato de la oposición". (D. Barros Arana. "Un Deccr. de la Historia de Chile", op. cit., vol 1, pp. 96 - 97).

"B. Loveman, "Chile The Legacy of Hispanie Capitalism". New York. Oxford University Press, 1979. p. 176.
} 
las "corporaciones municipales, alcaldes, gobernadores, subdelegados y párrocos, con la intervención de vecinos designados por ellos mismos, colocando así al cuerpo electoral en manos de los agentes del ejecutivo. Las inscripciones por poder, la recepción de los sufragios y los escrutinios mismo se prestaban a toda clase de abusos en beneficio de la autoridad imperante".

El presidente también tenía la facultad de nombrar a todos los magistrados del Poder Judicial, podía intervenir en la designación de todos los funcionarios públicos, era el jefe supremo de las fuerzas armadas, y en virtud del patronato también la lglesia estaba bajo su tuición ${ }^{9}$.

El nuevo gobierno dedicó atención especial a la reorganización del aparato represivo del Estado. Se reorganizó la policía de seguridad en los pueblos, particularmente en Santiago, creándose para tal efecto un cuerpo de vigilantes ${ }^{10}$. Para eliminar la posibilidad de intervención del ejército y de los antiguos militares en la gestión pública se llamó a retiro a un alto número de antiguos oficiales, no permitió el regreso de otros (O’Higgins entre ellos) que se encontraba en el exilio, y desterró a otros tantos ${ }^{\prime \prime}$. Asimismo. se reformó la Academia Militar, y para la influencia del ejército se creó la guardia nacional o cívica )"...obedecer a un jefe, emplear en ejercicios marciales las horas destinadas de ordinario a un ocio corruptor, hallarse inscritos en registro, tener una consigna, sentirse vigilado en el nombre del deber y del honor, ser amonestado o castigado a tiempo y un inmenso recurso para sujetar a los desmanes del pueblo y mejorar sus hábitos...") que, hacia mediados del año 1831, contaba ya en toda la República con veinticinco mil hombres "bien disciplinados":2, y cuya oficialidad estaba constituida por la juventud de la clase dirigente ${ }^{13}$. El poder y fuerza de la guardia cívica puede ser apreciado mejor al comparar su número de efectivos con el del ejército: hacia el año 1836, en vísperas de la guerra entre Chile y la Confederación PerúBoliviana, el ejército chileno contaba con unos dos mil setecientos hombres "distribuidos en las diferentes plazas del territorio, y cuya mayor parte (1.500) estaba encargada de defender la frontera del Bío-Bío de las frecuentes irrupciones de los indios araucanos" ${ }^{4}$.

Sin embargo, no obstante el carácter oligárquico y autoritario de la Constitución de 1833, hay coincidencia entre algunos historiadores en considerar que ella contenía elementos que en cierta medida evitaban el desborde del poder. Estos eran el entregar al Congreso la facultad de negar su voto al ministerio cuando lo creyera conveniente, el autorizar el cobro de los impuestos, y la de dictar anualmente los presupuestos de la nación, todo lo cual habría dado una cierta flexibilidad a la Constitución, introduciendo en su seno ciertos elementos de un régimen parlamentario ${ }^{15}$.

\section{¿EN TORNO A QUÉ PRINCIPIOS SE EFECTÚA LA LUCHA POLÍTICA?}

Al tomar el poder político las fuerzas socio-políticas triunfantes aspiraban a establecer, por una parte, un gobierno fuerte, centralizado, "cuyos hombres eran verdaderos modelos de virtud y patriotismo, y así enderezar a los ciudadanos por el camino del orden y de las

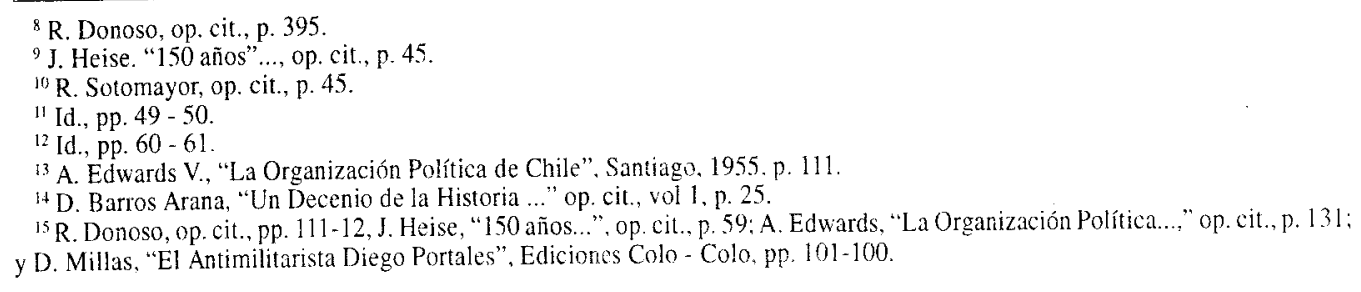


virtudes"16, y por otra parte, "constituir un Estado orgánico económicamente fuerte, asentado en el predominio comercial sobre el Pacifico"17.

Desde entonces se podrá apreciar un creciente predominio, en lo económico, de una política libre cambista que expresará los intereses básicos de las principales fuerzas sociopolíticas del país, de los grandes comerciantes importadores-exportadores y mayoristas, y de los mineros y fundidores del norte y sur del país. Siendo entonces, los sectores artesanales y aquellos interesados en crear y desarrollar una manufactura nacional los más perjudicados por esa política.

Aunque durante los años treinta y cincuenta hubo algunos intentos de aplicar, en cierto grado algunas medidas proteccionistas, ellas fueron gradualmente eliminadas. Y como ha sido indicado en trabajos anteriores, aquellas fuerzas políticas que como veremos luego, dedicaron todos sus esfuerzos al logro de una democratización de la estructura política nada hicieron, en cambio, por cambiar la política económica predominante. Por el contrario, su lucha por las libertades sociales y políticas la trasladaban también al plano económico y a la no injerencia del Estado en la actividad económica, esto es, a que no trabara la libre acción individual.

Con todo esto, la economia chilena fue acentuando su carácter casi exclusivamente exportador de materias primas minerales y de productos agrícolas. Se puede decir que hasta los comienzos de los años setenta el presupuesto de la nación se financió casi exclusivamente de las entradas provenientes de la exportación del cobre y, a partir de los años ochenta. de los ingresos provenientes del salitre.

Mientras había una cierta confluencia de intereses económicos entre los comerciantes y los terratenientes, y luego de los mineros, la inquietud política se expresa a través de una continua lucha en favor o en contra del gobiemo central y autoritario: "es así como toda la historia política en el período conservador (1830-1861) puede reducirse a una ordenada lucha de los dos principios, de los dos ideales que deben obrar en el seno de toda sociedad: la tendencia conservadora y la renovadora"s. Pero, si bien es cierto que el año 1861 se produce, en alguna medida, un cambio político al tomar el gobierno el Partido Liberal, se puede decir que sólo durante la primera mitad de los años setenta se verán resultados de una cierta significación de la política liberal al realizarse algunas reformas a la Constitución de 1833 y a la ley electoral.

Al interior de la alianza terrateniente-mercantil, que toma el poder político en 1830 , el

${ }^{16}$ Diego Portales, "Carta a Manuel Cea", Lima 10 de Febrero de 1822, citado por "F. Encina. Resumen de la Historia...", op. cit.. vol. 2. p. 850 .

${ }^{17}$ F. Encina, id., p. 899

18 J. Heise, "150 años...", op. cit., p. 61.

${ }^{19} \mathrm{D}$. Barros Arana, op cit, vol. 16, pp. 51.52. Pero, parece ser que las medidas proteccionistas que se umpulsaron en ese entonces se debieron, más que a una política deliberada del gobierno y de la fracción mercantil, a la acción de algunas asambicas provinciales. particularmente, en las de Santiago cuyos principales exponentes fueron Doningo Eyzaguirre y Manuel de Salas, (id., p. 52). Al respecto, el mismo D. Barros Arana comenta io siguiente: "Profesando las ideas más liberales en materia de comercio. Rengifo tenía, sin embargo, que someterse a las ideas llamadas proteccionistas. que cran las del común de las gentes. que iban en muchos casos hasta exigir la prohibición absoluta de la entrada a los artículos similares de los productos del país. que se elaboran en él. que según la ilusión de la inexperiencia, podían elaborarse. Perc. cuando por ley del 30 de agosto de 1833 fue autorizado el gobierno para nombrar comisiones que formasen las tarfas de avalúo de mercaderias axtranjeras para el pago de derecho de impuesto sobre bases razonables y equitativas para evitar el recargo exagerado de impuestos sobre ciertos artículos a título de protección de una industria nacional que no existió, ni existiría sin un cambio que forzosamente debía ser muy lento en las condiciones económicas del país". (id., p. 241). Entre las medidas adoptadas entonces fueron exención por diez años del pago de la contribución decimal. el cañamo y el lino que se cosechasen en el país. ofreciéndose un premio de dos mil pesos al que inventare y de a mil el que introdujera o construyera en Chile, imitando modelos extranjeros, la primera máquina que simplificarse o perfeccionase el beneficio de ambas plantas; se declaró libre de todo derecho la exportación de los productos de esta industria y se ordenó que los buques del Estado no usasen otras jarcias que la elaborada en el país; los buques de bandera nacional. que eran los únicos que podían hacer el comercio de cabotaje, fueron faculiados para transportar mercaderías extranjeras de un puerto a otro de Chile sin pagar impuesto de aduana en el puerto de su destino si lo hubieron pagado en el de sa salida. (id.. pp.. 241-42). Scgún D. Barros Arana, "todas estas gracias y excepciones fueron absolutamente estériles en sus resultados". 
elemento renovador lo constituía la fracción mercantil que fue la que impulsó las medidas que, para cumplir con su propósito de fomentar y dar facilidades al comercio, reformaron el antiguo sistema tributario y que reorganizaron los servicios en el ramo de la hacienda y que, en su comienzo y en cierta medida, abogaron por medidas proteccionistas ${ }^{19}$. Sin embargo, desde un comienzo se pudieron apreciar ciertas contradicciones al interior de la mencionada alianza. Esto ya se pudo observar en la comisión encargada de elaborar el proyecto de constitución: por un lado, la posición conservadora (representada por Mariano Egaña) abogaba por una completa reforma de la Constitución de 1828 para que en la nueva Constitución se asegurase al gobiemo bases más sólidas de existencia, "haciéndolo nacer no del voto inconsciente de la muchedumbre sino de los elementos más sanos de la sociedad, y revistiéndolo del poder suficiente para reprimir cualquiera tentativa anárquica" ${ }^{* 0}$. El otro sector, más innovador o liberal (representado por Manuel Gandarillas), temiendo que se pudiera convertir la reforma en una reacción franca en favor de una organización antiliberal y antidemocrática abogaba por la corrección de los defectos de la Constitución anterior y no por su cambio total: "sostenía que al paso que debian desaparecer las asambleas provinciales y todo lo que tendiese a embarazar la unidad gubernativa trabando la acción del poder ejecutivo, y dando pábulo a las competencias de autoridades y a la anarquia, era indispensable fijar límites razonables, claros y precisos al poder del presidente de lá República, establecer la responsabilidad efectiva de éste y de sus ministros y dar garantías sólidas a los derechos inalienables de los ciudadanos"-. En general, en la nueva Constitución predominó la posición conservadora.

Poco después, en el año 1832, el sector conservador, argumentando debilidad en el Ministro del Interior (Ramón Errázuriz) para mantener el orden interno y de indecisión para resolver un conflicto suscitado con la lglesia ${ }^{22}$, presionaron contra él obligándolo a renunciar, procediendo después a nombrar un ministro de sus filas.

Este conflicto puede ser considerado como el primero de una larga y continua serie de enfrentamientos ideo-políticos en torno a cuestiones religiosas y, en particular, sobre el patronato nacional. Al mismo tiempo, se acentuaron las diferencias en la coalición de gobierno dando origen poco después, en 1835, a un primer núcleo político denominado partido Filopolita compuesto, en gran parte, por antiguos "estanqueros" que se habían ido gradualmente distanciando de la política de Portales, que se acercaba cada vez más a los conservadores $^{23}$. Las diferencias entre los filopolitas y los conservadores se centraron, especialmente, en torno a dos cuestiones: en materia religiosa los filopolitas se declaraban más partidarios del patronato ${ }^{24}$, y en materia política abogaban por una cierta liberación del régimen político, cuyo punto concreto de discordia fue su proyecto de reincorporar al Ejército a los militares dados de baja después de Lircay, lo cual no logró aprobación en la Cámara ${ }^{25}$. Para contrarrestar las influencias y acción de los filopolitas, Portales se reintegró al gobierno como ministro, y el principal representante de dicho grupo, el Ministro de Hacienda Rengifo, debió presentar su renuncia. Con ello, perdieron su influencia en el gobierno.

\footnotetext{
${ }^{20}$ D. Barros Arana, id., p. 308.

2) Id., p. 308.

"2 Al ser expartiado el Obispo Rodríguez por sospectas de ser realista, en el año 1825. la diócesis de Santiago quedó acéfala. Al llegar a México, el Obispo Rodríguez nombró en su reemplizo a don José Eyzaguirre. pero entretanto el cabildo ectesiástico de la diócesis de Santiago había nombrado, a su vez. al deán de la iglesia Catedral don José Cienfuegos. Este fue el origen de un largo y complejo conflicto el cual debió ser enfrentado por el Ministro Errázuriz que, ai no dar una solución del agrado de los conservadores, debió hacer abandono del cargo.

${ }^{23}$ R. Sotomayor, op. cit., p. 435.

${ }^{24}$ Esta cuestión se manifestó de manera concreta a raíz del conflicto ereado por el proyecto que separaba el Seminario de Santiago del Instituto Nacional. El proyecto, justo en el fondo. se relacionaba con ciertos puntos de política y de derechos cclesiásticos que. en último término, daba auge a la enseñanza eclesiástica en detrimento de la enseñanza laica. (R. Sotomayor. op. cit.. 431 - 321 .

${ }^{25}$ F. Encina, "Resumen...", op. cit.. vol 2, p. 893.
} 
Pese a los poderes dictatoriales que la Constitución de 1833 otorgaba al Poder Ejecutivo y no obstante la violenta represión que éste ejercía contra los opositores, no se logró aquietar el descontento. Durante los tres decenios de los llamados gobiemos conservadores se pueden contabilizar por lo menos 17 conspiraciones, revueltas y motines, y dos guerras civiles, concentrándose éstas preferentemente en el primer y tercer decenio (de Prieto-Portales y de M. Montt respectivamente), esto es, durante los gobiernos más autoritarios del período.

Lo que en un comienzo constituyó lo que pudiéramos llamar la reacción natural de antiguos liberales o pipiolos vencidos en Lircay en su empeño por recuperar el poder político, fue adquiriendo posteriormente un carácter diferente. Las transformaciones sociales que experimenta la sociedad chilena debido a la evolución económica se expresaron especialmente a través del surgimiento y desarrollo de nuevas clases, capas y grupos sociales que, marginados de la directa participación política por el carácter oligárquico y no democrático del régimen político, entra en conflicto con los sectores dominantes.

El proceso de diferenciación social presenta diversas y complejas características, así como numerosas formas de expresión. Como lo fundamental en torno a lo cual se manifestará el quehacer político será la mayor o menor democratización del país y el logro de mayores libertades, se podrá apreciar una creciente difusión de nuevas ideas y un mayor número de enfoques sobre la concepción política de la sociedad, reflejando esto el creciente número de clases y grupos sociales que se incorporan a la actividad política del país. A su vez, esto se va manifestar en la formación y estructuración de partidos o agrupaciones políticas que van a expresar -cada vez de manera más duradera- los intereses y posiciones de los nuevos elementos o factores económicos y socio-políticos de la sociedad chilena.

\section{ORGANIZACIONES POLÍTICAS}

El auge de la minería, iniciado en la primera mitad de los años treinta, y el de la agricultura, provocado por la demanda de los mercados de California y Australia, tuvo como consecuencia inmediata el de dar mayor impulso al desarrollo de la burguesía minera y de reforzar el poder económico de la oligarquía terrateniente.

La burguesía minera se desarrolla en estrecho contacto con los intereses de las grandes casas comerciales extranjeras y nacionales, produciéndose de este modo una confluencias de ambos intereses. Este rasgo de la burguesía minera chilena ayuda a comprender, en gran parte, su papel contradictorio durante el siglo pasado. Mientras, por un lado, se constituye en la fuerza más dinámica de la economía y de los cambios en las relaciones de producción, por el otro, al dedicarse a una producción destinada casi exclusivamente al mercado mundial, se despreocupará a la larga de hacer inversiones e innovaciones técnicas en el proceso productivo minero, y al convertirse en un decidido defensor de la política librecambista disminuirá las posibilidades de desarrollo de la industria manufacturera chilena.

Las ideas liberales no eran algo exclusivo de determinados sectores socio-político: sino, desde los años cuarenta, tenían cada vez más adherentes en toda la sociedad del país. Para algunos (tales como Bilbao, Lastarria, Barros Arana, etc) ellas representaban la antítesis del régimen político establecido en 1830 , para otros ellas representaban la anarquía y e: desorden, pero, parece haber una gran coincidencia entre la mayoría de los sectores socioeconómicos, a excepción del artesanal y de la incipiente manufactura, de que ellas expre- 
san sus objetivos económicos, esto es, la no intervención del estado en la vida económica y la de aplicar una política de libre cambio. La oligarquía terrateniente procura mantener, en especial, el control del Poder Ejecutivo y el ideológico de la nación, dejando muchas veces que la política económica (en la cual coincide en general) en manos de la burguesía mercantil primero (Rengifo durante los años treinta), de la burguesía minera después (J. Urmeneta y G. Waddington durante el decenio de M. Montt), y posteriormente en manos del capital financiero (Melchor Concha y Toro y R. Sotomayor durante la administración de J. Pérez y A. Pinto $)^{26}$.

Lo anterior, si bien contribuye a explicar la relativa estabilidad política del período 1830-1891, también ayuda a entender la continua pugna de las nuevas clases y grupos sociales por ganar el poder político y no ser sólo participantes en su gestión. Por las facultades entregadas por la Constitución de 1833 el Poder Ejecutivo pasaba a controlar prácticamente todas las instancias del poder de la sociedad. De ahí entonces que la lucha política se expresará, en distintas formas, especialmente en el plano ideo-político, siendo las ideas liberales uno de los principales instrumentos empleados para lograr una cierta democratización que posibilitase a las nuevas clases sociales tener acceso al poder. Esto es particularmente importante si se considera que un amplio sector de la oligarquía terrateniente continuará manteniendo, por largo tiempo aún, un gran peso ideológico (ligado a la Iglesia), una gran base política (poder ejecutivo, legislativo y clientela electoral basada en la población de las zonas en que dominan, especialmente rurales), y un fuerte poder económico (de acuerdo a $F$. Encina, en la elección presidencial del año 1871, el dinero reunido por los hacendados conservadores para apoyar a su candidato fue de un millón de pesos oro de $44 \mathrm{~d}$., en tanto que los que apoyaban al candidato de la burguesía minera reunieron sólo 400 mil pesos) ${ }^{27}$.

La confrontación ideológica se efectuó principalmente a través de la prensa y de organizaciones político-culturales primero, y después a través de los partidos políticos que se iban organizando. Hacia el año 1843, dentro de un ambiente de relativa tolerancia política, se fueron creando asociaciones literarias o de estudios en donde a través de la lectura con un contenido liberal se aglutinaron aquellos que estaban animados de un afán innovador y que, a partir de abril de 1844, empezaron a entregar sus puntos de vista a través de diarios fundados por ellos mismos ("El Siglo", por ejemplo). Los conservadores efectuaron un procedimiento similar. Primero respondieron fundando un diario ("El Progreso") y después, al ver que ciertas publicaciones hacían una critica descarnada de la sociedad y del régimen político (por ejemplo, "La Sociabilidad Chilena" de F. Bilbao, y "La Guerra a la Tiranía"), provocando agitación en ciertos sectores de jóvenes, intelectuales y artesanos, procedieron a fundar, en el año 1845, una asociación, la "Sociedad del Orden", que tenía como propósito defender dicho principio ${ }^{28}$. Ante esto, los opositores formaron la "Sociedad Demócrata", organización "encargada de defender los derechos del pueblo, siempre atropellados, se decía, por la oligarquía dominante"29. Según D. Barros Arana, los fundadores de la "Sociedad Demócrata", interesados en lograr una influencia necesaria para participar en campañas electorales, promovieron la formación de una organización más popular ("que atrajera a su seno a la gente de la clase obrera"), fundando para tal efecto la "Sociedad Caupolicán" cuyo propósito principal era el logro del sufragio popular". Esta fue disuelta una año más tarde, en 1846. por orden del gobierno.

\footnotetext{
${ }^{26}$ F. Encina, "Resumen...", op. cit., vol 2, p. 1068: y William Sater. "Chile and the World Depression", op. cit.. p. 86: y F. Encina op. cit., vol 14, pp. $503-504$.

${ }_{27}$ F. Encina, "Resumen....", op. cit. vol., 2, pp. $1238-84$

${ }^{28}$ D. Barros Arana, "Un Decenio"”...", op. cit.. vol 1. pp. $484-85$ y 498 - 99. y vol. 2, pp. 70-72.

${ }^{24}$ Id., vol. 2, p. 73.

${ }^{30}$ Id., vol 2, pp. 74 - 75.
} 
Este fue el origen de un conjunto de asociaciones o clubes a través de los cuales se expresaban diversos enfoques, interpretaciones y concepciones sobre la sociedad y el tipo de régimen político que debía gobernarla. Sus puntos de vista eran variados. De aquellas que respaldaban y defendían las doctrinas liberales se desprendieron dos ramas principales: una que perseguía una transformación más profunda de la sociedad como un todo, constituida especialmente por jóvenes estudiantes, intelectuales, artesanos y algunos grupos de obreros; éstas son consideradas como precursoras de las organizaciones obreras de fines de ese siglo, las cuales, a su vez, son antecesoras de las organizaciones sindicales y políticas obreras que se formarán y desarrollarán durante el siglo $\mathrm{XX}^{31}$, siendo la más importante de ellas, por la influencia que tuvo en el momento de su actividad y posteriormente, la "Sociedad de la Igualdad" (1850) que agrupó a diversos sectores sociales en torno al lema: "La soberanía de la razón como autoridad de autoridades, la soberanía del pueblo como base de toda política. y el amor y fratemidad universal como base moral" 32 . En la otra rama se encuentran las organizaciones que representan especialmente a sectores de la burguesía e intelectualidad liberal que tienen como propósito fundamental efectuar reformas o transformaciones en lo político que les posibiliten ganar o tener acceso a los principales órganos de poder político.

Entre las primeras, como recién se enumeró, se encuentra la "Sociedad de la Iqualdad", cuya fundación fue impulsada, entre otros, por Santiago Arcos y Francisco Bilbao en el año 1850. Su objetivo principal era cambiar el régimen aristocrático existente, lo que debía ser logrado mediante la generación de un vasto movimiento democrático que debía sustentarse, sobre todo, en la fuerza del pueblo, en la acción de las clases trabajadoras. Sus fuentes de inspiración eran la experiencia de la Revolución Francesa y la de los movimientos liberales europeos de la primera mitad del siglo XIX (especialmente de los movimientos revolucionarios de 1848). En sus siete meses de vida lograron movilizar a centenares de obreros y artesanos de Santiago, estimándose que la Asociación llegó a contar con alrededor de cuatro mil miembros, a través de asambleas generales, reuniones de grupos, desfiles, etc.. y dieron inicio a una actividad que será imitada por casi todas las asociaciones obreras que le sucedieron más tarde: el establecimiento de cursos de difusión cultural a través de los cuales se enseñaba a leer y escribir, y se entregaban conocimientos de historia y geografía, aritmética, etc. ${ }^{33}$.

Dentro de la otra rama se destaca el "Club de la Reforma" fundado en Santiago en 1868 y en otras ciudades del país. Se formó en un momento que "marcaba una transición entre las antiguas formas y estilos de los pelucones y las nuevas que señalaba la doctrina liberal" 34 . Este era un momento en que las ideas liberales y anhelos de reformas habian alcanzado su maduración, ideas que. de acuerdo a V. Lastarria, debían fundirse en un partido que persiguiera la reforma en todas las esferas de la vida social, comenzando por la política: "La reforma verdadera es la política. Caiga el sistema represivo. el sistema colonial arbitrario y despótico, la dictadura del Jefe Supremo del Estado. con su Constitución y todas las leyes políticas que formasen su organización “ $\cdots 5$

\footnotetext{
${ }^{3}$ Entre 1850 y 1878 se pueden encontrar por lo menos siete de estas wsociaciones: "La Soctudad ce la lgualdad" de Santiage (1850), el "Club de la Opinión" de Valparaíso (1858), "La Sociedad Unión Republican." en varias ciudades (1868 en Vallenar y en 1876 en Valparaíso). La "Sociedad de la Igualdad" (le Valparaíso (1872). La "Sociedad Republicana Francisco Bibao" de Coronel (1878). Todas se fijaban como objetivos propagar las ideas liberales y mejorar las condiciones de vida de los trabajadores. $\mathrm{H}$ Ramírez N. Historia del Movimiento Obrero ... op. cit., pp. 82 - 84).

${ }^{32}$ Sergio Guilisasti Tagle, "Partidos Politicos Chilenos", Santiago. 1964. p. 132

${ }^{33}$ H. Ramirez, op. cit, pp. $80-81$.

${ }^{34}$ Patricio Estellé, "El Club de la Reforma de 1868 - 1871". en "Historia". Universidad Católica de Chile. Santiago, 1970, pp. $11 !$ y 117.

Citado por P. Estellé. op. cit., p. 116.
} 
Eran ideas que reflejaban el grado de desarrollo socioeconómico alcanzada por la sociedad chilena. Un momento en el cual la burguesía mercantil y la minera llegaban a una etapa de desenvolvimiento que se encauza hacia el desarrollo de una burguesía financiera ligada al capital bancario. No es extraño. entonces. que al fundarse el Club de la Reforma, en septiembre del año 1868, figurase como presidente de la Directiva de esta entidad el magnate minero y de la banca Jerónimo Umeneta. y que se haya establecido como principio principal de su Programa la reforma electoral y de la Constitución Política del Estado ${ }^{36}$.

Toda esta actividad comenzó a dar frutos en el año 1871 al aprobarse la disposición que prohibía la reelección del Presidente de la Repúbicica, y las reformas a la ley electoral y a la Constitución que le siguieron poco después. Esto no era otra cosa que la culminación de un proceso que se había iniciado, por así decir, en el momento mismo en que se promulgó la Constitución de 1833, estrechamente ligado al desarrollo de las condiciones materiales e ideológicas del país.

La lucha ideológica que caracterizaba el período en estudio se encuentra referida, principalmente, a dos aspectos íntimamente interrelacionados: las cuestiones religiosas y las relacionadas con la democratización del país. Entre las primeras está siempre presente el problema de la tolerancia religiosa, y entre las segundas, aquellas que se refieren especialmente a la reforma de la Constitución, la libertad electoral y de imprenta.

Los progresos que se habían realizado en materia de tolerancia religiosa durante los primeros años de vida independiente sufrieron un serio traspié cuando en la Constitución de 1833 se suprimió el artículo cuarto de la Constitución anterior, de 1828 , que establecía que nadie sería perseguido ni molestado por sus opiniones privadas. El poder que adquirió la Iglesia y el clero católico a través de la Constitución de 1833 se reforzó al disponerse en la ley de imprenta de 1839 que "merecería la calificación de blasfemo todo impreso que atacara los dogmas de la religión católica, apostólica, romana, o que contuviera expresiones ofensivas al respeto a Dios, a la Santísima Virgen y a los Santos..."37.

Como era de esperar, esto provocó gran reacción en la población que sustentaba ideas liberales y en aquellos que profesaban otras creencias religiosas. Hasta los años setenta se pueden contabilizar por lo menos ocho incidentes (entre otros, la cuestión de la "Primera Capilla de Protestantes de Valparaíso", la "Enseñanza Religiosa en las escuelas privadas, la "Cuestión de los Cementerios", la "Cuestión del Sacristán", etc.), siendo cada uno de ellos objeto de apasionadas discusiones políticas. Esto obedecía, sin duda, a un reordenamiento de la fuerzas socio-políticas del país que, en su lucha contra la influencia de la iglesia -que en aquel entonces perseguía la hegemonía en toda la vida social-, procuraban desplazar a los sectores conservadores del control político. Estos conflictos pueden ser considerados, entonces, como expresiones y causas de las transformaciones económicas, sociales y políticas que experimenta el país, lo cual tuvo, entre otros, el efecto de acelerar el proceso de diferenciación ideo-política, dividiendo a los partidos que expresaban los intereses y concepciones socio-políticas de nuevas clases y grupos sociales.

El primer partido que vive este proceso de reordenamiento fue el tradicional Partido Conservador o Pelucón. Después de la escisión que sufrió con el retiro del gobierno de los filopolitas debió enfrentar, hacia el año 1840, un nuevo conflicto interno en el cual se aprecia con creciente nitidez la diferenciación que se produce en su interior: "Como consecuencia del choque de las candidaturas de Tocornal y de Bulnes, la alta aristocracia, los elementos más religiosos y en general los conservadores de corte antiguo, se agruparon en tomo a

${ }^{3 /}$ Id., pp. $118-19$ y 122.

${ }^{37}$ R. Donoso, op. cit. pp. $191-92$. 
Tocornal, mientras los nuevos ricos, los jóvenes, el elemento medio, el personal judicial y el de la enseñanza, reconocían la jefatura de Montt" ${ }^{\prime 38}$. En torno a estas tendencias se van a ir formando dos grupos: el que representa a la antigua aristocracia pelucona, que comenzaron a ser denominados ultramontanos (porque abogaban por la conservación de los privilegios civiles y políticos de la Iglesia) y el que expresa las posiciones de los llamados conservadores reformistas, progresistas o liberales. Este antagonismo se acentuó en la década siguiente, durante el gobierno de Montt (1850-1860), influyendo en esto, con seguridad, el período de prosperidad de la agricultura ${ }^{39}$. Aun más claramente se expresó esta diferencia en la composición del Congreso de 1855: "Los ultramontanos quedaron predominando en el Senado, y los futuros nacionales en la Cámara de Diputados"40)

El quiebre definitivo al interior de las fuerzas conservadoras se produjo finalmente en los años 1856-57. El factor detonante o formal que provocó este desenlace fue un incidente religioso (la "Cuestión del sacristán"), ante el cual las fuerzas conservadoras reformistas. progresistas o liberales, se agruparon en tomo a Montt y Varas, formando primero lo que se llamó Partido Montt-Varista y, poco después, Partido Nacional.

De este modo, hacia los años $1856-57$ se pueden encontrar tres partidos políticos: el Conservador Clerical-Ultramontano, el Nacional y el Liberal Progresista, encontrándose en avanzado estado de gestación al futuro partido Radical.

El Partido Nacional nació en base al programa de gobierno de Montt, cuyos principios fundamentales eran: constituir la nación mediante el afianzamiento del orden ("cueste lo que cueste") el cual debía imponerse a través del principio de autoridad y la formación del hábito de respetarlo; a su juicio, sólo un gobiemo fuerte, activo y creador puede afianzar el orden; la democracia efectiva sólo sería realidad cuando el desarrollo de las aptitudes y de las virtudes cívicas la hagan posible; en su opinión, las reformas políticas, en el mejor de los casos, sólo conducirían al enervamiento del gobierno eficaz, existiendo una alta probabilidad de que se produzca la disolución del Estado si antes no se consolida en forma inconmovible el principio de autoridad y el hábito del orden; por el momento, lo esencial era transformar al ciudadano, inculcarle hábitos de trabajo, moralidad, virtudes cívicas y, sobre todo, el desarrollo de su personalidad mediante la enseñanza; en lo religioso se pronunciaban por el patronato por ser parte de la soberanía nacional ${ }^{41}$. Al momento de su formación se aglutinó en torno al Partido Nacional la burguesía minera, tanto del cobre (los Umeneta) como la del carbón (M. Cousiño), los Gallo y los Matta de la zona minera de Copiapó, y jóvenes liberales (D. Barros Arana, Alejandro Reyes). Sin embargo, los primeros en abandonarlo fueron los Matta y los Gallo que fundarían poco después el Partido Radical, y los jóvenes liberales. Otros, como el magnate minero y de la banca Jerónimo de Urmeneta, "compartía el espíritu de orden y de progreso de Montt y de Varas, pero no la necesidad de imponerlos de arriba hacia abajo; juzgando por él mismo y por lo que había visto en los Estado Unidos. creía que bastaba mantener condiciones favorables al desarrollo de la iniciativa individual, para que ésta realizara el milagro yanqui. Y como él pensaba su hermano José Tomas, Cousiño

\footnotetext{
${ }^{38}$ F. Encina, op. cit., vol. 13, p. 177

34 "El rápido desarrollo de la riqueza, que fue consecuencia de los mercados de Californias de Australia para los productos de la agricultura, y del auge del mineral de plata de Chañarcillo, improvisó grandes fortunas: 3 cas i todos los nuevos ricos, sin arraigo en el pasado, se agruparon al principio en tomo a Montt y de Varas, con quienes tenian mis afinidad que con la aristocracia pelucona. cuyas preocupaciones no compartían". (F. Encina, op. cit., rol 13, p. 212). O bien: "Muni y Varas prosiguieron la grandiosa estructuradora que debía ser el asombro y la envidia de la América española. mientras que lus pulueonés absortos en la venta de sus trigos, charquis, fripoles, lentejas, garbanzos, ajies, oréganos, etc., para Californı y Australia se hacian sordos a las exhortaciones de los ultramontanos miliares, que los instaban a derribar cuanto anies al ministro, que su ojo dirisaba con seis años de anticipación como el sucesor de Montt". (F. Encina. op. cit., vol 13. p. 182).

${ }^{40}$ Id., p. 183

${ }^{+1}$ Id., vol. 12 , pp. $263-63$

${ }^{42}$ Id., vol. 15. p. 358.
} 
y los demás"42.

El Partido Conservador, con la escisión sufrida al formarse el Partido Nacional, "se parecía como dos gotas de agua a lo que era el partido pelucón antes de su alianza con los estanqueros" ${ }^{\prime 3}$. Al producirse la división, agrupó a los terratenientes más conservadores, a los ultramontanos, en estrecho vínculo con la política de la Iglesia ("En el nuevo partido conservador reina la unidad religiosa absoluta“). despreocupándose o desplazando a un lugar subalterno el desarrollo económico del paíst.

El Partido Liberal o Progresista adquirió contornos de partido el año 1849. Su origen parece encontrarse más exactamente en el partido o grupo filopolita, que se desgajó de la coalición de gobierno a mediados de los años treinta. Llamados primero filopolitas, después fueron conocidos como conservadores progresistas, luego progresistas a secas y finalmente liberales. Impulsados por J. V. Lastarria y un grupo de jóvenes (surgidos del llamado "renacimiento literario" de 1842) se fijaron como objetivo político el lograr una mayor libertad, teniendo como tarea inmediata la de procurar una disminución de las facultades del Poder Ejecutivo. En un manifiesto ("Bases de la Reforma”) que resume el programa de aspiraciones liberales, Lastarria aboga por la necesidad de enmiendas constitucionales y legales: ampliación del sufragio, incompatibilidades parlamentarias, supresión del estado de sitio, abolición de mayorazgos ${ }^{45}$. Posteriormente, en el año 1859, al constituir con los conservadores la "Fusión Liberal-Conservadora" (que gobierna entre 1861 y 1871), un grupo de liberales avanzados se escinde para contribuir a formar el Partido Radical o "Rojo" "4.

El Partido Radical, por su parte, tiene sus raíces más próximas en la "Sociedad de la Igualdad". A partir del año 1850, se comienzan a vincular a Lillo (que encabezaba esa asociación) los Matta, los Gallo y otros, que difundieron los postulados de la "Sociedad de la Igualdad" fuera de Santiago, prendiendo vigorosamente en Copiapó y la Serena ${ }^{47}$. Desde entonces se va estructurando paulatinamente la nueva organización. fundándose como tal en el año 1859, definiendo tres años más tarde (1862) de manera más precisa los postulados al radicalismo: reforma de la Constitución política, enseñanza laica, descentralización administrativa, libertad electoral ${ }^{48}$.

La acción de las fuerzas socio-políticas del país, su lucha ideo-política y el graduaí relativo cambio de las relaciones de fuerza comenzó a tener resultados hacia los años setenta. En el terreno de la libertad de imprenta, su actividad se encauzó hacia la derogación o reforma de la ley de imprenta de agosto de 1846 . cuyo proyecto se basó en el presentado por el conservador $M$. Egaña en 1839: el primer título se refería a los delitos cometidos por la imprenta y las penas.

La ley de 1828 había establecido las penas en alternativa, es decir, multa pecuniaria y prisión en caso de que la primera no fuera pagada, y eran moderadas, no excediendo aquellas, aún en los casos más graves, de seiscientos pesos y la prisión de sesenta días. Sólo al delito calificado de sedicioso en tercer grado correspondía la pena de expatriación o presidio por cuatro años. El proyecto de Varas iba mucho más lejos que el fracasado de Egaña, pues imponía a todo delito de prensa, cualesquiera que fuese su calidad y su grado, multa y prisión, haciendo extensiva esta última a seis años por escritos sediciosos... Las disposiciones relativas al establecimiento de una imprenta, a la publicación de un periódico y a la responsabilidad del impresor estaban inspiradas en un propósito severamente represivo, como no

\footnotetext{
${ }^{44}$ Id., pp. $264-71$.

${ }^{45}$ Sergio Guilisasti, op. cit., pp. $74-75$.

${ }^{46}$ ld., p. 75.

${ }^{47}$ Id., p. 132.

${ }^{48}$ Id., p. 133.

${ }^{49}$ R. Donoso, op. cit., pp. 361 - 62 .
} 
se había formulado desde la independencia" $\$ 9$. Fuertemente impugnada y combatida desde su promulgación, esta ley estuvo a punto de ser derogada en el año 1849, cuando esa iniciativa fue aprobada en la Cámara de Diputados, pero al ser rechazada en el Senado, continuó en vigencia. Aunque en la práctica le fue muy difícil al gobierno el poder aplicarla, se mantuvo hasta julio del año 1872 , fecha en que fue finalmente derogada ${ }^{50}$.

El lograr una mayor libertad electoral fue otro de los objetivos de lucha de las fuerzas más progresistas del país ya que, como se ha dicho, la Constitución y la ley electoral vigentes impedían el acceso al poder político a aquellas fuerzas socio-políticas que no controlaban el poder ejecutivo. En el año 1842 se efectuó la primera modificación a la ley electoral por la cual se derogó la disposición al articulo 81 que confería a los gobernadores la facultad de imponer penas por los delitos electorales, pero una ley promulgada ese mismo año, en vez de introducir modificaciones políticas más profundas consagró incluso disposiciones contrarias a la Constitución, "pues ésta quiso que la elecciones de senadores fueran calificadas por el Senado, la de Presidente de la República por el Congreso, y que la condición de saber leer y escribir se hiciera efectiva desde 1840 sin distinción alguna" ${ }^{\text {1. }}$. Este estado de cosas se mantuvo hasta el año 1861, cuando por ley de 13 de septiembre, se efectuaron modificaciones a las dos leyes electorales anteriores: se confió las funciones electorales a las municipalidades y se estableció el registro electoral permanente y no renovable cada tres años; para los efectos de la inscripción no se les computaba la renta en calidad de tales a los soldados y clases del ejército permanente y de los cuerpos de policía, se suprimió la prohibición de calificarse a los eclesiásticos regulares, a los jomaleros y patrones y se suprimieron las calificaciones por poder; exigió para todo calificado la condición de saber leer y escribir. $\mathrm{Y}$, aunque conservó, en sus líneas generales, la estructura de 1833, se manifestó más liberal en lo relativo "al orden y libertad de las elecciones, a los delitos en materia electoral, a las causas de nulidad y casos en que debían repetirse" 52 . Una nueva ley, del año 1869, permitió la entrada a los mayores contribuyentes en la organización del sistema electoral, confiándoles una facultad que antes había correspondido a las municipalidades (se introdujo el sistema de Juntas Revisoras, compuesto por siete individuos elegidos al azar por la municipalidad entre los cuarenta mayores contribuyentes); se exigía la comparencia personal del individuo que pretendía calificarse y se restableció la prohibición absoluta de inscribirse a los soldados y clases del ejército permanente; se facultó a la Comisión Conservadora la tarea de hacer imprimir y repartir las boletas de calificación y se introdujo la reforma de abolir los certificados de inscripción, que antes se daban por razón de cambio de domicilio o pérdida del boleto de calificación, fuente de abusos y corruptelas ${ }^{53}$. Cinco años más tarde, en noviembre de 1874, se aprobó una nueva reforma, complementaria a la erimienda constitucional promulgada ese mismo año, que modificaba la elección de los senadores, según la cual la elección de los senadores debía hacerse por provincias, en votación directa, por el sistema de lista completa, lo cual, a juicio de R. Donoso. tuvo un efecto decisivo "en acelerar el progreso democrático, en restar influencia al ejecutivo, en acentuar el papel del Congreso y abrir el paso a un régimen parlamentario, expresión de las corrientes dominantes en la opinión pública" ${ }^{4}$.

Paralelamente al logro de reformas a la ley electoral se habian acentuado en la misma medida las presiones para modificar la Constitución. En agosto de 1867 se promulgó la ley que declaraba reformable por el Congreso la de Constitución de 1833. En tomo a dicha

\footnotetext{
sid. pp. $37 i-73$.

sid., p. 401.

52 Id., pp. $413-14$

id.. pp. 4 i6 - 17

Id. p. 424.
} 
aspiración se agruparon los adherentes del Club de la Reforma, los Montt - Varistas o Partido Nacional y el Partido Radical. Después de ser aprobado por la Cámara de Senadores en diciembre del año 1870 y en la de Diputados en octubre de 1873 , se promulgó finalmente el proyecto que modificaba la Constitución. Sus disposiciones principales fueron: sobre la composición del Senado se establecía que la elección de Senadores, que antes se hacía por toda la República se haría en adelante por provincias; cada provincia elegiría un senador propietario por cada tres diputados o fracción de dos, lo que elevaba el número de senadores, que antes era fijo y sólo alcanzaba a veinte, a una cifra mayor que guardaba proporción con el número de diputados; cada provincia elegiría un senador suplente, y los senadores que antes funcionaban por nueve años, funcionarían en adelante por sólo seis años ${ }^{55}$. En cuanto a las facultades extraordinarias se eliminó el inciso seis del artículo No 36 ("Autorizar al Presidente de la República para que use de facultades extraordinarias, debiendo siempre señalarse expresamente las facultades que se le conceden y fijan un tiempo determinado a la duración de esta ley"), pasando dicha facultad a ser parte de las atribuciones del Congreso: "Dictar leyes excepcionales y de duración transitoria, que no podrá exceder de un año, para restringir la libertad personal y la libertad de imprenta, y para suspender o restringir el ejercicio de la libertad de reunión, cuando lo reclame la necesidad imperiosa de la defensa del Estado, de la conservación del régimen constitucional o de la paz interior... Si dichas leyes señalaran penas, su aplicación se hará siempre por los tribunales establecidos... Fuera de los casos prescritos en este inciso, ninguna ley podrá dictarse o restringir libertades o derechos que asegura el artículo 12"56. Respecto a las incompatibilidades parlamentarias se estableció, entre otras, que no pueden ser elegidos diputados los eclesiásticos regulares, los párrocos y vice-párrocos, los jueces letrados de primera instancia, los intendentes de provincia y los gobernadores de departamentos. Y, por ley de diciembre de 1888 (promulgada como reforma constitucional en julio de 1892) se dispuso que todo empleo, función o comisión públicos retribuidos, serán incompatibles con el cargo de diputados o senador, y se hicieron extensivas a estos últimos todas las disposiciones dictadas sobre la materia ${ }^{57}$.

Todo esto fue acompañado de otras medidas legislativas que tuvieron como consecuencia producir lo que R. Donoso llama el "ocaso de la influencia de la Iglesia". En sesión de 19 de julio de 1875 del Senado se pronunció por unanimidad en favor de la supresión del fuero eclesiástico, y "al resolver la cuestión de la atribución de la Corte Suprema dio al artículo 25 una redacción según la cual, cuando las competencias tuvieran lugar entre un tribunal civil y otro eclesiástico, si la Corte Suprema resolvía que el conocimiento del asunto correspondía al primero "las resoluciones de éste sólo producirán efectos civiles". De acuerdo con esta fórmula, la Corte Suprema de Justicia no podía impedir al tribunal eclesiástico siquiera conociendo del asunto que correspondía a la justicia ordinaria, y se denegaba el auxilio del brazo secular para el cumplimiento de las sentencias del tribunal eclesiástico" 58 . Más tarde, pese a la oposición de la iglesia ("el proyecto, al reducir el matrimonio a un contrato puramente civil, iba contra la moral y los dictados elementales de la razón..."), por ley de enero de 1884 se ponía fin a un debate que se arrastraba por decenios, se legisló sobre el establecimiento del registro y del matrimonio civil cuyo artículo primero disponía: "El matrimonio que no se celebre con arreglo a las disposiciones de esta ley, no produce efectos civiles... Es libre para los contrayentes sujetarse o no a los requisitos y formalidades que prescriba la religión a que pertenecieren... Pero no tomarán en cuenta estos requisitos y

\footnotetext{
${ }^{4}$ F. Encina, op, cil., vol. 15, p. 302.

${ }^{5}$ Id., p. $302, y$ R. Donoso, p. 474.

${ }^{57}$ R. Donoso, op. cit., pp. 483 y 487.

${ }^{58}$ Id. p 289
} 
formalidades para decidir sobre la validez del matrimonio, ni para reglar sus efectos civiles" "59, y ese mismo año se promulgó la ley complementria que creó el servicio del registro civil con funcionarios del Estado, encargados de llevar el registro de los nacimientos, matrimonios y defunciones, "con lo cual se arrebató toda ingerencia de la Iglesia en la constitución de la familia"60. Por último, en esos mismos años se procuró acentuar la política reformista al proponerse la separación de la Iglesia y el Estado mediante la eliminación del artículo quinto de la Constitución, encontrando esto, sin embargo, una fuerte oposición en los sectores conservadores, y no mayor apoyo del Gobierno. Esto se logrará sólo cuarenta años después, con la Constitución de 1925.

Todas estas reformas están señalando el momento de transición política que vive el país durante el cual se produce el desplazamiento del poder ejecutivo de los conservadores por las nuevas fuerzas socio - políticas liberales que expresan los intereses y concepciones de la burguesía minera y de la financiera claro está, un carácter limitado, y de clase. Por una parte, si bien es cierto que amplían la base de participación democrática en la estructura política del país, ésta continúa manteniendo su rasgo oligárquico: sólo la reforma electoral de 1970, que concedió derecho de voto a analfabetos, significó la ampliación del cuerpo electoral a más de un 45 por ciento de la población total del país; en 1925 el electorado representaba un 7,1\% de la población y en 1958 el $21 \%$. Por otra parte, al adquirir el régimen un creciente carácter parlamentario con el consiguiente debilitamiento del Poder Ejecutivo, las fuerzas de oposición ganaron mayor capacidad de acción política en el Congreso: en la primera elección efectuada después de las reformas políticas para renovar el Congreso, los resultados fueron los siguientes: de 37 senadores elegidos, 15 fueron del partido de gobierno (Alianza Liberal), 16 de la oposición y 6 independientes; en la Cámara de Diputados, de 108 diputados, 43 pertenecían a la combinación gobernativa, 37 a la oposición y 28 independientes ${ }^{62}$.

Desde el año 1856-57, cuando se escinde el Partido Conservador y se forma el Nacional, y luego el Radical, hasta el año 1891, fecha en que se produce la acción política que derribó al Presidente Balmaceda, constituye un nuevo período de reordenamiento y de consolidación de los partidos políticos chilenos.

En el partido Conservador se manifestaron dos corrientes principales, una que aconsejaba la conciliación de la enérgica defensa política de la religión con la abstención del clero en la política meramente partidista, y otra que tenía como propósito implantar el catolicismo en todas las instituciones públicas y privadas y "de aplastar a los incrédulos, los anticlericales, los masones, los protestantes y los nacionales y aún a los liberales no fusionistas" $\%$. Durante un tiempo predominó esta tendencia intransigente, pero paulatinamente ganó más fuerzas la primera, que encauzó su lucha por la libertad electoral y el debilitamiento del poder ejecutivo. En el año 1878 aprobó un Programa mediante el cual se propugna la descentralización administrativa; ampara las libertades electorales, de asociación, de prensa, de enseñanza; sostiene las incompatibilidades parlamentarias y se manifiesta defensor decidido del catolicismo ${ }^{64}$. Según F. Encina, este programa era "el mismo de la juventud reformista nacional-radical, si se despoja a esta última de los postulados sobre la libertad de pensamiento y de culto y la secularización de las instituciones" ${ }^{* 5}$. Posteriormente, en su cuarta

\footnotetext{
${ }^{54}$ Id., p. 308; y F. Encina op. cit., vol. 18, pp. $168-70$.

R. Donoso, op. cit., p. 308; y F. Encina. op. cit., vol. 18, pp. $168-70$.

". Hernán Godoy U., "Estructura Social de Chile", Santiago, 1972, p. 413.

R. Donoso, op. cit., p. 425.

${ }^{n}$ F. Encina, op. cit., vol. 15 , pp. 352 y 355

${ }^{\text {th }}$ Id., vol. 15, p. 355; y S. Guilisasti, op. cit. p. 23.

${ }^{n}$ F. Encina, op. cit., vol. 15, p. 355
} 
Convención Nacional (1895), el Partido Conservador tomó acuerdos para conservar el "Orden Social Cristiano", prestando mayor atención a la cuestión social y a la clase obrera. siguiendo en este sentido a la Encíclica "Rerum Novarum" de León XIII ${ }^{66}$. Separado del gobierno en el año 1873, retorna a él después de la revolución de 1891 y participa en la mayoría de los gobiernos que le suceden hasta el año 1938, cuando triunfa el Frente Popu$\operatorname{lar}^{67}$.

El Partido Nacional, de gran fuerza política al momento de su formación fue sufriendo continuas divisiones y, después de elegir 20 senadores de un total de 37 en el año 1876 , comienza a decrecer gradualmente, obteniendo en 1894 sólo cinco parlamentarios, desapareciendo después de esa fecha ${ }^{68}$.

El Partido Liberal, al distanciarse del Partido Conservador en 1873 (poniendo fin a la "Fusión Liberal-Conservadora") y al convertirse en partido de gobierno, "había adquirido el poder suficiente para enfrentar en las urnas a todos los demás bandos reunidos..." ${ }^{\text {, }}$, lo cual le permitió gobernar entre 1875 y 1891. Después de esta fecha sufrió un rápido desquiciamiento. Un grupo Balmacedista o Liberal Democrático se transformó, en 1894, en la segunda fuerza del país. Posteriormente se reintegró al Partido Liberal, propiamente dicho ${ }^{70}$.

El Partido Radical fundó la Primera Asamblea Radical en Copiapó en el año 1863 y, poco después, otra en La Serena. Un año más tarde fundó una nueva Asamblea en Santiago, presidida por Manuel Antonio Matta, y en 1865 inicia sus actividades la Asamblea de Concepción. Su primera representación en el Congreso la obtuvo en la elección de 1870 (ocho parlamentarios), y en 1888 ya contaba con siete diputados y siete senadores ${ }^{71}$. En el año 1875 pasó a formar parte del gobierno al formarse la Alianza Liberal-Radical bajo cuyo mandato se reforma la Constitución de 1833. En noviembre de 1888 se efectúa la Primera Convención del Partido Radical en el cual se aprueba su primer programa, declarándose que "el Partido Radical es un 'Partido autónomo' y 'que su existencia sirve al desarrollo de la libertad y de la República', propugnando el respeto al derecho de sufragio; la libertad individual; la autonomía municipal; la separación de la Iglesia del Estado; la independencia del Poder Judicial; la enseñanza primaria gratuita, laica y obligatoria; el mejoramiento de la condición legal de la mujer; la reducción del número de empleados públicos; el mejoramiento de la condición de los proletarios y de los obreros"72.

¿Cuál era la situación orgánica de la clase trabajadora? En cuanto a los trabajadores del campo no hay antecedentes, o al menos nosotros no lo tenemos, de que hayan tratado de organizarse sindical o políticamente. Con relación al movimiento obrero, H. Ramírez sostiene que en el período que se extiende desde los orígenes del proletariado hasta el año 1879 , "la clase obrera evoluciona desde su calidad de núcleo incipiente, cuantitativamente débil, disperso, sin organización de ninguna especie, hasta constituir una clase social relativamente numerosa... que vive en centros urbanos más o menos densos, que empieza a adquirir los primeros rudimentos de una conciencia de clase y que también empieza a bosquejar formas elementales de organización y de lucha"7?.

\footnotetext{
S. Guilisasti, on cit., p. 23

${ }^{6} 7$ Id., p. 24

"Gi Germán Urzúa Valenzuela, "Los Partidos Políricos Chilenos". Suntiago. 1968. p. 32.

6) Fencina, op. cit., vol, 15, p. 363.

${ }^{70} \mathrm{G}$. Unzúa $V$, op. cit. pp. $56-57$

7 S. Guilisasti, op cit. pp. 132 - 33; y G. Urzúa op cit. pp 42 - 4.

is. Guilisasti, op cit., p. 134.

${ }^{73}$ H. Ramirez, "Historia del Movimiento Obrero..." op. cut. . . 127.
} 


\section{ORGANIZACIONES SINDICALES Y POLÍTICAS OBRERAS}

Se ha podido constatar que ya en 1834 se produjeron las primeras rebeliones obreras en el mineral de Chañarcillo, que, al repetirse poco después, "provocaron una enorme inquietud en Copiapó mismo, en donde la población llamada La Placilla era como una amenaza constante"74. También se produjeron este tipo de manifestaciones en la región de Concepción y algo más tarde, en 1849, se efectuó una huelga organizada por los operarios de sastrerías de Santiago. Entre esta fecha y 1878 se pueden contabilizar por lo menos 19 huelgas, movimientos, rebeliones o incidentes callejeros obreros en distintos lugares del país ${ }^{75}$.

A estas primeras rebeliones, que expresaban un grado incipiente de conciencia de clase, de carácter espontáneo, ya es posible encontrar un gradual desarrollo, de modo que hacia el año 1865 ya es posible encontrar algunos escritos que reflejan un mayor reconocimiento del papel de la clase obrera en la sociedad ${ }^{76}$. Hacia el año 1847, y especialmente desde 1853 , se comienzan a formar las primeras sociedades obreras y de artesanos (la "Sociedad Tipográfica" de Santiago, 1853; la "Sociedad Tipográfica" de Valparaíso, 1855; la "Sociedad de Artesanos" de Valparaíso y la "Unión de Artesanos" de Santiago, 1858; la "Sociedad Unión de Artesanos" de Santiago y la "Unión de Artesanos" de La Serena, 1862), todas las cuales fueron de carácter mutualista, o sea, "respondían al anhelo de encontrar en el propio esfuerzo de los trabajadores una solución a los problemas económicos-sociales que sobre ellos recaían; mediante la práctica del ahorro, el socorro mutuo y el cooperativismo, los trabajadores procuraban ponerse a cubierto -ellos y sus familias- de los peligros que con mayor frecuencia los amenazaban la cesantía, enfermedad, invalidez y muerte"77.

Confirmando nuestro examen de la evolución económica del país y del desarrollo de las relaciones capitalistas de producción, el nivel de organización del movimiento obrero chileno comienza a tener su mayor impulso desde lós años ochenta después que se integran las salitreras al país y cuando se comenzó a fomentar más sistemáticamente el desarrollo de la industria manufacturera nacional. En el año 1870 habían 13 sociedades mutualistas, reconocidas por el gobierno; en 1880,39 y hacia el año 1924,600, con 90.000 miembros, aparte de aquellas que buscaban reconocimiento legal ${ }^{78}$. Durante el último tercio del siglo XIX se puede observar además la presencia de otras dos formas de asociaciones obreras: las sociedades de resistencia y las mancomunales.

Las sociedades de resistencia, influidas por ideas anarquistas provenientes de Argentinas, fueron más comunes entre los obreros industriales y portuarios que entre los mineros; se concentraron geográficamente en la zona central del país, especialmente en Santiago, y Valparaíso, estimándose que hacia fines de siglo existían una treintena de tales organizaciones. que luchaban por un horario y por mejores condiciones de vida y de trabajo ${ }^{79}$. Las

\footnotetext{
${ }^{74}$ Roberto Hernández, "Juan Godoy o el descubrimiento de Chañarcillo", tomo I. p. 69. citado por H. Ramírez. op. cit., p. 131.

${ }^{75}$ H. Ramírez, op. cit., pp. $133-34$.

${ }^{76}$ En un artículo del diario "El Copiapino", de 15 de marzo de 1865, se dice: "A nosotros que formamos la clase obrera, cuya clase por su inmensa mayoría es la base principal que sostiene el cdificio social, y que por un derecho legítimo somos acreedores a doble significación social que la que hasta ahora se nos concede, y que por el contrario, ocupamos una esfera bastante triste, a nosotros digo, nos incumbe trabajar con constancia y entusiasmo para conseguir tan digno objeto; y lo conseguiremos precisamente, pues sólo consiste en nuestra voluntad si tomamos por norte de nuestras aspiraciones". (H. Ramírez, op. cit.. p. 139).

H. Ramírez, op. cit., p. 167.

Alan Angell, "Politics and the labour Movement in Chile", London, 1972, p. 14. De acuerdo a H. Ramirez, en el año 1900 habían más de 300 de estas asociaciones. (op. cit., p. 266).

A. Angell. op cit. p. 16.
} 
mancomunales o hermandades fueron una forma más elevada de organización obrera que se desarrollan, especialmente, desde comienzos del presente siglo. La mancomunal era una organización estrictamente proletaria (para ser miembro de ella"... se requiere -decía se reglamento- pertenecer a la clase obrera"), que contó entre sus dirigentes a Luis E. Recabarren, quién, "a través de una activa propaganda, fue orientado la institución en un sentido cada vez más combativo, y dotándola de una ideología mas definida" ${ }^{\circ 0}$.

Un indicador del grado de desarrollo que comienza a experimentar el movimiento obrero es su interés por unir a las diversas asociaciones existentes en el país. Así, siguiendo el ejemplo dado por las sociedades mutualistas de Valparaíso, que en 1888 formaron la Liga de Sociedades Obreras, en Santiago y en Iquique se hizo lo mismo; en Santiago, el mes de Junio de 1894, "se reunieron los representantes de ocho instituciones para poner las bases de la Confederación Obrera de Sociedades Unidas. Después de una serie de gestiones, el 23 de septiembre de ese mismo año quedó instalada con la participación de diez y nueve sociedades. Poco tiempo después de establecida, a comienzos de 1895, la Confederación Obrera de Santiago tomó la iniciativa para convocar a un Congreso Nacional de Sociedades Obreras..."

El primer intento de organizar un partido que se enlazara más directamente con la clase obrera se efectuó en noviembre de 1887. Su formación fue impulsada por un grupo de exradicales que, ante la imposibilidad de encauzar al Partido Radical por un curso que tendiera en forma acelerada a la realización de la revolución democrático-burguesa ("En orden a la riqueza pública, como una de las necesidades más premiosas se hacen sentir en el país y como el único medio de procurar el engrandecimiento y la prosperidad de la República, el Partido Radical proclama la más decidida protección a la industria nacional"), se separaron de esa organización política y fundaron el partido Democrático que, entre otros, se fijó como objetivo "...la emancipación política, social y económica del pueblo" $"$. Si bien esta organización no fue, estrictamente hablando, un partido genuino de la clase obrera, alcanzó gran raigambre popular, pudiéndose decir que es "el primer partido auténticamente popular, de masas que hubo en Chile" ${ }^{83}$. Al mismo tiempo fue una escuela política para los futuros dirigentes obreros, como Luis E. Recabarren, que comienzan a aplicar y difundir el socialismo científico. Ya en el año 1893 se advierte entre algunos de sus miembros el convencimiento de que al Partido Democrático le correspondía poseer una orientación definidamente socialista; después de numerosos intentos se concretó la aspiración de tener un partido de ese tipo al fundar Luis E. Recabarren, en el año 1912, el Partido Obrero Socialista.

La actividad socio-política del movimiento obrero iba en ascenso. Se ha estimado que entre 1884 y 1889 hubo alrededor de 60 conflictos laborales, y se ha constatado que entre 1911 y 1920 se efectuaron 293 huelgas que abarcaron a más de 150.000 trabajadores $^{\$ 4}$. En el año 1909 se formó la Federación Obrera de Chile (FOCH) sobre bases mutualistas, "con finalidades de asistencia social, de mejoramiento económico (formar cooperativas de consumo crédito en dinero a sus asociados fomento del ahorro, seguros contra enfermedades, de

\footnotetext{
${ }^{8 i s}$ H. Ramíre7. op. cil. P1. $269-70$.

Id. pp. $266-67$.

: 1d., pp. 209 y $214-15$

${ }^{83}$ ld., p. 216.

". H. Ramírez, "Historia del Movimiento. Obrero... " op. cit. pp. 283 - 85: y Federico Gil. "The Political System of Chile". Boston, 1966 , p. 54 .

"Julio César Jobet. "Ensayo Crítico del Desurrollo Econónico - Social de Chile." Santiago. 1955. p 144
} 
vida, de desocupación forzosa) y de perfeccionamiento moral y cultural (lucha contra el alcoholismo, creación de escuelas, teatros, bibliotecas, periódicos, dictación de conferencias)" $" 85$.

En su segunda convención, en el año 1917, se acuerda agrupar en la FOCH a toda la masa asalariada del país, y en su tercera convención, en el año 1919, se aprobaron nuevos estatutos y se adoptó una nueva declaración de principios en la cual se proclama "la total eliminación del régimen capitalista y declaraba que, eliminando este sistema, correspondería a la FOCH tomar el control de toda la economía nacional y asumir sus responsabilidades"86. Se estima que, hacia los años 1918-19, la FOCH contaba con 60.000 miembros, disminuye a 30.000 en 1922, y en el año 1924 este número se habría elevado a 140.000; por otro lado se ha constatado que en el año 1925 existían 24 sindicatos que contaban con 204.000 miembros ${ }^{87}$. 